\title{
ALGUMAS ACHEGAS PARA O ESTUDO DA INDÚSTRIA NO DISTRITO DE VISEU (1850-1900)*
}

\author{
António Rafael Amaro **
}

\section{INTRODUÇÃO}

Muitos são os autores que, recentemente, têm feito referências sobre a necessidade de se elaborarem trabalhos monográficos e circunscritos no espaço, sobretudo no que concerne ao estudo da indústria. Espera-se destes estudos, entre outras coisas igualmente importantes, um conhecimento mais em profundidade das reacções dos vários sectores industriais, ao verem-se confrontados, como aconteceu na segunda metade do século XIX, com uma crescente integração e necessidade de especialização - no quadro de uma cada vez maior divisão social do trabalho - dos mercados nacionais e internacionais. Não é possível, a nosso ver, encontrar respostas minimamente fundamentadas para questões como, por exemplo, o nosso relativo atraso industrial, reacção ao livre-câmbismo e proteccionismo, impacto da modernização dos transportes, inovações tecnológicas e condicionamentos à mudança dos processos produtivos, se não no quadro de espaços de análise mais restritos, ainda que em estreita relação com o todo nacional.

Em Portugal - tal como entre os países que mais cedo se industrializaram, esclareça-se - regiões houve que, por razões múltiplas e ainda hoje controversas, responderam melhor aos novos desafios económicos postos pela industrialização. Ao invés, outras zonas do país tardaram - igualmente por importantes e variados factores que urge deslindar- a encontrar o caminho que as levaria a acompanhar essa modernização do seu tecido produtivo. Pagaram, com isso, uma factura muita alta, marcada pelo crescente atraso económico, que acabou por condicionar a necessidade de um desenvolvimento relativamente equilibrado para o país.

Pode-se sempre argumentar que não há apenas um modelo de crescimento económico e que não existe uma causalidade directa entre industrialização e desenvolvimento. Contudo, pelo menos no que diz respeito à segunda metade do século XIX e grande parte do século seguinte, e no quadro europeu, para não se ir mais longe, não se pode ignorar que os países mais industrializados acabaram

\footnotetext{
** Instituto Universitário de Desenvolvimento e Promoção Social — Pólo de Viseu da Universidade Católica Portuguesa.
} 
por impor, directa e indirectamente, um modelo de desenvolvimento que não deixou muita escolha (Pereira, 1974: 7-28). E, a confirmá-lo, está o facto de países ou regiões que não se industrializaram verem, em poucas décadas, aumentar o fosso económico que progressivamente os separava. Realidade que não se fez sentir apenas a nível do crescimento económico, mas que viria a contribuir, também, para uma crescente acentuação das assimetrias a nível do desenvolvimento, seja qual for o ângulo em que este conceito, ainda controverso ${ }^{1}$, se analise.

$O$ presente artigo limita-se a ser um estudo exploratório sobre a indústria no distrito de Viseu, durante a segunda metade do século XIX. Ainda assim, tem consciência o seu autor de que não passa de um curto e limitado contributo. Porém, ele é já o produto de uma reflexão resultante de um projecto mais vasto que pretendemos vir a realizar, como tese de doutoramento, para o conjunto da Beira Interior. Aí, assim o espero, serão então equacionadas muitas das problemáticas enunciadas nos parágrafos anteriores

Por isso pretende o presente trabalho não ir muito mais além do que fornecer algumas achegas, com base em fontes de momento disponíveis, sobre a estrutura de uma actividade, a indústria, num distrito em que a terra e o comércio ocuparam, desde sempre, a quase totalidade da mão-de-obra disponível. Realidade económica e social que não foi apenas característica do período que aqui nos ocupa, mas que, bem pelo contrário, acabou por manter-se, quase inalterável, até aos nossos dias. Todavia, não desconhecemos que, à semelhança do conjunto do país, nas décadas que se seguiram à Segunda Guerra Mundial, o distrito de Viseu procurou acompanhar o sentido da modernização económica que então se estava a operar. Porém, apesar desse esforço modernizador, a estrutura produtiva não sofreu alterações significativas, podendo mesmo afirmar-se, paradoxalmente, que este período, que vem até à década de oitenta, ficou marcado por ser o segundo momento - o primeiro registou-se na segunda metade do século XIX - de alargamento do fosso, aliás como aconteceu a outras regiões, que separava este distrito, em termos económicos e de índice de ocupação ligada ao sector secundário, da média nacional (Nunes, 1991:716). Aliás, o distrito de Viseu é, no país, dos poucos - como, recentemente, demonstrou a autora anteriormente citada, com base nos índices de população activa por sectores de actividade —que permaneceu durante o século XX sem oscilações de posição (acompanhado apenas, neste caso, pelos distritos de Bragança e de Vila Real), dentro das características daquilo que a referida autora considerou como Região Agrícola (idem: 718). ${ }^{2}$.

Resta-nos, nesta introdução, justificar alguns dados que trouxemos à colação, sobre a estrutura demográfica. Fizemo-lo, apenas, com o sentido de salientar a ligação, que sabemos existir, entre ruralidade ou, se quisermos, entre a inexistência de grandes aglomerados urbanos e a débil industrialização. 


\section{ALGUNS DADOS SOBRE A POPULAÇÃO NO DISTRITO DE VISEU}

A população portuguesa registou, durante o século XIX, um crescimento sem precedentes. Não obstante o nosso atraso económico, em relação aos países mais desenvolvidos do velho continente, a população portuguesa quase que duplicou, em apenas um século. Em 1801, o número de residentes no país andava à volta dos 2931 930, cem anos depois a soma atingia já os 4660 095. Este crescimento, apesar de tudo, como se sabe, não acompanhou os valores atingidos no conjunto dos restantes países europeus, «cuja população duplicou entre 1801 (índice 100) e 1886 (índice 199), enquanto Portugal se quedou por um nível substancialmente inferior [...] cifrando-se no índice 155 naquela última data»(Cascão, 1993:425).

No caso do distrito de Viseu, a fazer fé nos dados de que dispomos, o aumento da população não andou muito longe do quadro demográfico nacional. Não temos, por ora, elementos seguros para os anos anteriores a 1835, mas tendo em conta o crescimento da população nos anos que se lhe seguiram, podemos afirmar que o seu aumento foi um facto irreversível (cf. QUADRO I). Assim, se, em 1835, a população do distrito se quedava pelos 233 866, em 1900 contava já com 402 259, registando um crescimento real de 168393 habitantes. Crescimento populacional que correspondeu a um aumento médio anual - tendo em conta os 65 anos que medeiam entre 1835 e 1900 - de 2590 pessoas. Resultado, a nosso ver, bastante positivo, sobretudo se tivermos em consideração que o distrito de Viseu foi um dos mais atingidos pelo fluxo emigratório que afectou parte do país ${ }^{3}$ - só entre 1855 e 1890 terão saído legalmente de Portugal 406000 pessoas, número que deve ser acrescido de 10 a $13 \%$ de ilegais - na segunda metade do século XIX (Cascão, 1993: 425). A emigração, nesta altura, como é sabido, foi um fenómeno maioritariamente masculino (a proporção das mulheres não ultrapassou os 10\%); partiram sobretudo os mais jovens e os mais capazes. Este facto, só por si, teve de facto influência directa sobre a evolução da população e, indirectamente, não deixou de ter consequências, nem sempre fáceis de quantificar, a nível da natalidade. 


\section{QUADRO I}

EVOLUÇÃO DA POPULAÇÃO NO DISTRITO DE VISEU (1835-1900)

\begin{tabular}{|l|l|}
\hline Anos & População \\
\hline 1835 & 233866 \\
1838 & 287957 \\
1841 & $289038^{*}$ \\
1854 & 303736 \\
1858 & 325692 \\
1861 & 336844 \\
1864 & 353543 \\
1872 & 368961 \\
1878 & 371571 \\
1890 & 391015 \\
1900 & 402259 \\
\hline
\end{tabular}

Fontes: Censo da População do Reino de Portugal (1890 e 1900), Lisboa, Imprensa Nacional, 1896 e 1905, respectivamente.

* Como na fonte utilizada aparece o quantitativo de 389 038, depreendemos que se trata de uma gralha, daí a alteração

Apesar de tudo, o distrito de Viseu era, em 1864 - data da realização do $1 .{ }^{\circ}$ Censo da população nacional credível -, uma das regiões do país que, em termos de densidade populacional, se situava bastante acima da média do país. Pois, se tivermos em consideração que, nesta data, no continente nacional, por cada quilometro quadrado, habitavam 43 pessoas, enquanto no distrito de Viseu a relação subia a 75, ficamos com a ideia que esta região se encontrava relativamente equilibrada em termos populacionais. Com uma densidade superior ao distrito de Viseu, só Aveiro (76), Viana do Castelo (85), Braga (114) e, por fim, o Porto (164).

Nada surpreendente, tendo em conta a estrutura económica do distrito, vincadamente agrícola, são os dados apresentados pelo Censo de 1864, quanto à percentagem de pessoas a viver em aglomerados considerados rurais. Para um conjunto de 353543 habitantes, 339300 residiam fora de centros urbanos $(95,97 \%)$. Saliente-se, contudo, que estes números decorrem do critério adoptado pela comissão responsável pelo referido Censo. Critério que apenas considerou população urbana os residentes que habitassem em centros com mais de 2000 almas. Razão pela qual só os habitantes das cidades de Lamego e Viseu, respectivamente com 7844 (curiosamente com mais habitantes do que a sede do distrito) e 6399 habitantes, é que, no conjunto do distrito, foram considerados como população 
urbana. Daí que, de acordo com o critério estabelecido, apenas $4,3 \%$ da população residente merecesse o epíteto de urbana.

Ainda assim, se tivermos em consideração que a percentagem de população urbana nacional andava pelos $11,43 \%$, podemos dizer que, por esta altura (1865), ainda não se faziam sentir as diferenças que o século XX claramente acentuou. Deparamos mesmo, curiosamente, com distritos do Litoral - casos de Leiria (98,32\% e Aveiro (97,32\%) - com índices de ruralidade superiores aos de Viseu. Menor admiração causa, por certo, o facto de outros distritos do denominado interior, como são os casos de Vila-Real $(97 \%)$, Guarda $(97,15 \%)$, Bragança $(96,46 \%)$ e Castelo Branco $(96,97 \%)$ registarem índices de ruralidade superiores aos de Viseu.

A grande distância destas médias de ruralidade encontarava-se o distrito de Lisboa - sobretudo, por esta zona se assumir, então, como o principal pólo industrial do país, a par do Porto, - que contava com uma população urbana na casa dos $42,28 \%$.

Tendo ainda o ano de 1864 como referência, podemos dizer que a população feminina no conjunto do distrito de Viseu era, em número, ligeiramente superior à masculina - 168118 homens e 185425 mulheres. Uma diferença, favorável ao sexo feminino, de 17307 (9,4\%) que, no seu conjunto, estabelecia uma relação, em números redondos, de 90 homens por cada 100 mulheres Esta maioria feminina mantém-se para o conjunto da população solteira: 119950 mulheres solteiras para 109841 homens $(91,5 \%)$. Sabendo nós que o fluxo emigratório afectou bastante o distrito e que aquele foi esmagadoramente masculino - a proporção das mulheres emigrantes, para o século XIX, nunca ultrapassou os $10 \%$-, não podemos deixar de salientar que a relação, entre os dois sexos, não se afasta do que é considerado normal no quadro do paradigma demográfico nacional $(91,8 \%$ de homens).

Acresce, ainda, que o quadro demográfico que temos vindo a traçar não se alterou, substancialmente, oito anos depois. Para um conjunto de população, em 1872, de 368961 habitantes, a diferença favorável às mulheres baixou mesmo para 16 945, passando a representar, no conjunto da população, apenas mais $8,8 \%$ do que os homens. Contudo, como se pode ver pelo quadro seguinte (QUADRO II), esta relação não é, naturalmente, igual no conjunto dos 26 concelhos que, na altura, faziam parte do distrito de Viseu. Curiosamente, dois concelhos - casos dos concelhos de Armamar e de Mondim - subvertiam mesmo a estrut:ıra dominante e apresentavam uma população em que os seus habitantes eram maioritariamente homens.

O QUADRO II dá-nos, ainda, uma ideia bastante clara do peso relativo, em termos de habitantes, de cada concelho no conjunto da população distrital. São grandes as diferenças entre o concelho que $e$, ao mesmo tempo, capital do distrito, com 45611 habitantes, e o pequeno concelho de S. João de Areias, com apenas 4028. 
Acima de 20 mil habitantes contam-se apenas 4 concelhos: por ordem decrescente, Viseu, Tondela, Lamego e Cinfães. Entre 10 mil e 20 mil habitantes, encontramos 13 concelhos, enquanto que os restantes 9 não chegam, cada um deles, a atingir os $10 \mathrm{mil}$ habitantes.

Já no que diz respeito ao número médio de habitantes por fogo, as diferenças não podem ser consideradas de monta, se tivermos em conta a sua variação : entre 3,5 habitantes por fogo para um concelho, por exemplo, como o de Armamar e 4,6 habitantes por fogo para o concelho de Oliveira de Frades, que regista o valor mais elevado. A média do distrito, como é evidente, também não se afasta muito destes valores $(3,9)$.

\section{QUADRO II}

DISTRIBUIÇÃO DE FOGOS E HABITANTES POR CONCELHO (1872)

\begin{tabular}{|l|c|c|c|c|c|}
\hline Concelhos & Fogos & $\begin{array}{c}\mathbf{N}^{0} \text { médio } \\
\text { por fogo }\end{array}$ & Homens & Mulheres & $\begin{array}{c}\text { Total } \\
\text { (hab.) }\end{array}$ \\
\hline ARMAMAR & 3000 & 3,5 & 5321 & 5275 & 10596 \\
CARREGAL & 2856 & 3,9 & 5232 & 5942 & 11174 \\
CASTRO-DAIRE & 4847 & 3,8 & 8878 & 9622 & 18500 \\
SANTA COMBA-DÃO & 1845 & 3,9 & 3612 & 3673 & 7285 \\
FRÁGUAS & 1659 & 3,9 & 3143 & 3364 & 6507 \\
S. JOÃO DE AREIAS & 1227 & 3,2 & 1873 & 2155 & 4028 \\
LAMEGO & 6121 & 4,1 & 12300 & 12881 & 25181 \\
MANGUALDE & 4683 & 3,9 & 8866 & 9663 & 18549 \\
MOIMENTA DA BEIRA & 2884 & 3,9 & 5564 & 5853 & 11399 \\
MONDIM & 1654 & 3,9 & 3235 & 3219 & 6454 \\
MORTÁGUA & 2150 & 3,9 & 4033 & 4459 & 8492 \\
NELAS & 2964 & 4,1 & 6057 & 6382 & 12430 \\
OLIVEIRA DE FRADES & 1920 & 4,6 & 3933 & 5022 & 8955 \\
S. PEDRO DO SUL & 4418 & 4,4 & 8932 & 10525 & 19457 \\
PENALVA DO CASTELO & 3021 & 4,1 & 6116 & 6543 & 12659 \\
PENEDONO & 1681 & 3,9 & 3187 & 3485 & 6672 \\
PESQUEIRA & 3581 & 3,8 & 6640 & 7196 & 13836 \\
REZENDE & 4846 & 3,8 & 8916 & 9717 & 18633 \\
SÁTÃO & 3013 & 4,1 & 6033 & 6475 & 12508 \\
SERNANCELHE & 3045 & 4,0 & 5792 & 6396 & 12188 \\
CINFÃES & 6256 & 3,3 & 9806 & 11077 & 20883 \\
TABUAÇO & 2338 & 3,3 & 3895 & 3937 & 7832 \\
TAROUCA & 1689 & 3,4 & 2804 & 3068 & 5872 \\
TONDELA & 7030 & 4,0 & 13452 & 14982 & 28434 \\
VISEU & 11270 & 4,0 & 21720 & 23891 & 45611 \\
VOUZELA & 3355 & 4,4 & 6648 & 8169 & 14817 \\
\cline { 2 - 6 } & 93362 & 3,9 & 176008 & 192953 & 368961 \\
\hline
\end{tabular}


Mais difícil do que tudo o que apresentámos até aqui, assim pensamos, se torna a tarefa de medir, com precisão, o significado destes valores para o homem concreto, que se vê apanhado na teia de um quadro geral, naturalmente enganador. Ou seja, os valores médios aqui apresentados quanto não escamotearão a verdade, dado que nada nos dizem sobre a qualidade, natureza e condições dos fogos inventariados, nem tão pouco das diferenças entre, por um lado, famílias numerosas e, por outro, famílias reduzidas a uma ou duas pessoas. Na impossibilidade, por ora, de responder a esta questão, vejamos de seguida, em traços largos, uma parte da realidade económica do distrito de Viseu, através da sua estrutura industrial. Todos sabemos que não foi este o sector económico mais importante para as gentes que, durante o século XIX, aqui viveram e laboraram. Porém, a indústria não deixou de interessar e preocupar todos os que nesta região procuraram encontrar, fora da agricultura, outras formas de viver e de trabalhar.

\section{A INDÚSTRIA NO DISTRITO DE VISEU}

O quadro demográfico anteriormente traçado, sobretudo no que concerne ao escasso número de pessoas que habitavam em espaços considerados urbanos é, só por si, revelador do domínio claro que as actividades agrícolas detinham no distrito e, por outro lado, do fraco desenvolvimento industrial de toda esta região. A este propósito, lembra David Justino: «Sendo resultado de um processo global de aprofundamento da divisão social do trabalho, o fenómeno da urbanização, no quadro geral da Europa dos dois últimos terços do século XIX, não poderá ser entendido independentemente dos processos de industrialização e terciarização que marcaram profundamente essa época» (Justino, vol. II, 1988: 371).

É, portanto, no quadro da ruralidade que devemos entender o domínio da indústria doméstica e/ou oficinal que caracterizou esmagadoramente o distrito, durante o século XIX. E, por isso, não nos deve admirar a importância que as feiras e mercados sempre tiveram nesta região, pois elas representam, lembra o autor citado anteriormente, «um factor de compensação e superação das insuficiências da estrutura urbana»(idem: 372 ).

O domínio da pequena indústria, as vincadas características rurais e a importância que o comércio tinha no distrito, sobretudo através das suas feiras e mercados, não escaparam à análise da comissão encarregue, em 1881, de fazer o levantamento industrial do país. Assim, os técnicos responsáveis pela elaboração do conhecido Inquérito Industrial de 1881, perante a quase inexistência de fábricas dignas desse nome, deixaram o seguinte testemunho: «no districto de Vizeu soubemos que, estando a propriedade muito dividida, as populações se entregam de preferência à agricultura, podendo dizer-se que não há lá indústria fabril, e que nunca existiu» (Inquérito Industrial, vol. II, 1881: 56) Contudo, acrescentam 
ainda: «O districto de Vizeu, pela sua situação no centro do paiz, está em circumstancias de ser o que tem sido realmente: o mercado onde affluem os produtos fabris e agrícolas das provincias do norte», pois «No valor de centenas de contos eram as transacções que se faziam na feira annual conhecida pelo nome de Feira Franca de Vizeu [...], que foi e ainda é hoje a principal feira portugueza» (idem ). Irrefutável, portanto, era o facto de no distrito haver muito comércio «e que nas duas vidas, a agricola e a commercial, se emprega[va]m exclusivamente, por assim dizer, os seus habitantes» (idem ).

QUADRO III

ORIGEM DAS PRINCIPAIS MERCADORIAS NA FEIRA DE S. MATEUS (1854)

\begin{tabular}{|l|l|}
\hline \multicolumn{1}{|c|}{ Origem } & \multicolumn{1}{c|}{ Mercadorias } \\
\hline PORTO & $\begin{array}{l}\text { Panos a retalho, fazendas brancas, ourivesaria, retrosaria, tamancos, } \\
\text { fatos, sola, algodões, latoaria e linho } \\
\text { Panos a retalho, fazendas brancas, ourivesaria, chapéus, artigos de cor- } \\
\text { reeiro, sapatos, tamancos, sola, ferro, produtos de mercearia, relógios e } \\
\text { louça. }\end{array}$ \\
$\begin{array}{l}\text { LAMEGO } \\
\text { COIMBRA }\end{array}$ & $\begin{array}{l}\text { Fazendas brancas, quinquilharias, ferro e louça. } \\
\text { GUIMARÃES } \\
\text { BRAGA }\end{array}$ \\
$\begin{array}{l}\text { Ourivesaria, ferragens, toalhas e guardanapos. } \\
\text { Chapéus, atacadores e sapatos. }\end{array}$ \\
OVAR & $\begin{array}{l}\text { Panos por atacado e a retalho } \\
\text { Peixe de escabeche }\end{array}$ \\
COVO & Vidros
\end{tabular}

Fonte: David Justino, vol. I, 1988:292

Mas, se a Feira de S. Mateus era a mais importante e conhecida do distrito - basta dizer que, no ano de 1854 , os valores estimados das transacções que aqui se efectuaram rondaram os 1000 contos de réis (Justino, vol. II, 1988: 290) - , em Mangualde realizava-se também uma feira anual que, pela sua situação estratégica, não lhe ficava muito atrás em importância económica, sobretudo para o comércio têxtil. Na opinião de David Justino, esta feira acabava «por ser uma das mais importantes no comércio interno de lanifícios produzidos na região da Serra da Estrela em geral e dos das fábricas da Covilhã em particular» (idem:286). Na vila de Mangualde possuíam os mais poderosos fabricantes da Covilhã importantes armazéns de tecidos. Em Mangualde se abastecia, de produtos têxteis, o norte do país, com especial destaque para o Minho e Trás-os-Montes. 
No ano de 1854, por exemplo, foram transaccionados na feira de Mangualde produtos no valor de 96 contos de réis. Representando os têxteis, sobretudo lanifícios, $62,7 \%$ do valor total (idem: 287). Não admira, tendo em conta o que ela representava para o sector dos lanifícios, que David Justino tenha visto na feira de Mangualde «um autêntico barómetro do estado da indústria da Covilhã» (idem). Em abono desta tese, cita mesmo uma notícia publicada na Revista Agrícola, de Março de 1869, que dá claramente esta ideia: «A feira de Mangualde esteve em completa apatia por escassez de numerário. Se a feira de Março não estiver mais animada, os fabricantes da Covilhã vêem-se obrigados a diminuir o numero de operários» (idem).

\section{QUADRO IV}

RESIDÊNCIA DOS PRINCIPAIS COMERCIANTES PRESENTES NA FEIRA DOS SANTOS DE MANGUALDE, NO ANO DE 1854

\begin{tabular}{|l|l|l|l|}
\hline BRAGA & ÁGUEDA & GOUVEIA & SABUGAL \\
GUIMARÃES & MOLELOS & PINHEL & MANTEIGAS \\
PORTO & VISEU & ALVERCA & SEIA \\
RESENDE & P. DO CASTELO & ALMEIDA & S. ROMÃO \\
V.N DE FOZ CÔA & FRAGOSELA & JARMELO & COVILHÃ \\
AVEIRO & MOURAZ & GONÇALO & ARGANIL \\
EIXO & NELAS & TRINTA & COIMBRA \\
ARRANCADA & MESQUITELA & MEIOS & FIG. DA FOZ \\
\hline
\end{tabular}

Fonte: David Justino, vol. 1, 1988:288

Perceber-se-á agora melhor a importância que as feiras e os mercados tinham para o distrito deViseu, em particular, e para a Beira Interior, em geral. As feiras anuais de S. Mateus, em Viseu, e a dos Santos, em Mangualde - que, como é evidente, não eram as únicas (só em Lamego existiam cinco feiras anuais e um mercado mensal e, no conjunto do distrito, realizavam-se 25 feiras anuais e 58 mensais) - eram as principais responsáveis pelo facto de esta região funcionar, no dizer de David Justino, «como autêntica placa giratória [...], centrifugando os produtos das várias regiões que a ela concorrem» (idem: 290).

Não estamos em condições de dizer que este facto, só por si - ou, até mesmo, pela centralidade geográfica do distrito, entre o interior e o litoral, o norte e o sul, mais sujeito, sem dúvida, a tentações de domínio económico por parte de regiões, ou pólos, mais industrializados -, tivesse sido determinante para o fraco desenvolvimento industrial que acabou por caracterizar o distrito, durante o século XIX. Aparentemente, seria até lógico pensar-se o contrário. A centralidade geo- 
gráfica e a existência de tão importantes feiras no distrito - pelas facilidades que estas proporcionam na transacção de produtos, acumulação de capitais, ou, mesmo, na troca de experiências e ideias - poderiam até ter sido importantes factores de crescimento económico. Crescimento que, bem aproveitado, poderia ter sido gerador de uma dinâmica capaz de conduzir ao almejado desenvolvimento industrial. Contudo, não foi isso o que se passou.

A comissão incumbida da realização do Inquérito Industrial de 1881, ao referir-se à inexistência de indústria no distrito de Viseu, deixou escapar, com alguma resignação e fatalismo, que esta região, devido à sua situação geográfica, mais não podia ser que $\mathrm{o}$ «mercado onde affluem os produtos fabris e agrícolas das províncias do norte». Esta conclusão dos responsáveis pelo Inquérito Industrial - retirado o seu peso fatalista - coloca, a nosso ver, uma questão pertinente. A saber: a situação geográfica do distrito de Viseu, estratégica, em termos económicos, nas ligações Norte - Sul e Interior - Litoral, explica a sua importância de interposto comercial que, por sua vez, inibe o desenvolvimento industrial. Por outras palavras, $\mathrm{o}$ facto de aqui afluir toda a qualidade de produtos tornou esta zona farta $\mathrm{e}$ muito concorrencial, condicionando, assim, os investidores locais.

Não creio que este seja o único, ou até o mais importante factor, para o fraco desempenho industrial desta região. Contudo, não podemos deixar de salientar que, em face da situação geográfica do distrito, alguns factores que, à primeira vista, se nos apresentam como positivos, podem resultar num efeito contrário. Atentemos no seguinte: o distrito de Viseu, para além de sofrer dos inerentes custos de interioridade - fracas ligações, por exemplo, com o Litoral, quer fluviais quer terrestres -, não beneficiava da mesma protecção que outras regiões vizinhas menos expostas. Era o caso da indústria de lanifícios da Serra da Estrela. A ser assim, não restava a esta região outro caminho que não fosse o de desenvolver o sector industrial de modo a poder concorrer com os três pólos industriais que, nos meados do século XIX, se afirmavam em Portugal e que, só por si, representavam cerca de $2 / 3$ da força produtiva industrial do país: a norte o Porto, a sul Lisboa e no interior a Covilhã (cf. Justino, vol. II, 1988: 84). Ora, como é fácil de ver, o distrito de Viseu não só se encontrava intrincheirado entre os limites dos interesses económicos dos centros polarizadores do norte e do sul (Porto e Lisboa), com os quais obviamente não tinha condições de concorrer, como, mesmo ao seu lado, tinha a forte concorrência industrial, sobretudo têxtil — lanifícios, da Covilhã.

Fossem quais fossem as razões, é um facto, Viseu, a sua região, acabou por cair, em termos industriais, na órbita de um grande centro do interior como era a Covilhã, sendo ainda objecto de cobiça e presa relativamente fácil de um outro pólo, como era o Porto. Vimos já qual a origem dos principais comerciantes que transaccionavam os seus produtos nas feiras de Mangualde e Viseu, assim como salientámos o domínio que os industriais de lanifícios da Serra da Estrela e da 
Covilhã aí detinham. Ora, se para outros sectores ainda temos algumas dúvidas, relativamente à tese que acabamos de expor, já o mesmo não acontece sobre o efeito atrofiador que os lanifícios da Covilhã tiveram, em relação à indústria doméstica de tecidos de lã, com tradições na região.

Acompanhemos então de perto, com as fontes disponíveis, o que aconteceu à importante indústria doméstica de tecidos de lã (Burel), existente no distrito, no decurso do século XIX. Fradesso da Silveira, no seu livro As Fábricas de Portugal, dizia existirem no distrito, nos meados do século XIX, entre 1600-1700 tecedeiras. Ora, quando da realização do Inquérito Industrial de 1881, comentando precisamente estes dados, os inquiridores afirmaram não existir no distrito qualquer fábrica de tecidos de lã e que a estatística das contribuições, compulsada pelos responsáveis do Inquérito Industrial, já só referenciava a existência de 425 tecelões, 29 indústrias caseiras de cardação e 47 estabelecimentos de apisoar (Inquérito Industrial de 1881, vol. II:78). Assim, não só o número de tecelões tinha diminuído, poucos anos depois do levantamento feito por Fradesso da Silveira, como, mais importante ainda, a tradicional indústria doméstica acabou por não evoluir no sentido da criação de fábricas que, através da modernização dos processos produtivos, tentassem responder aos novos desafios criados pela industrialização e pela concorrência nacional e internacional.

Tanto no caso da tecelagem, como no da cardação ou do apisoamento - apesar de muitas vezes nas estatísticas se lhes referirem como fábricas - estamos em presença de uma indústria doméstica que, a maioria das vezes, ocupa apenas uma pessoa. Não passam, portanto, de indústrias rudimentares que visavam unicamente o comércio local, quando não era apenas o consumo familiar. Sediavam-se, por norma, estes estabelecimentos nas próprias casas de habitação, ocupando apenas, em estreita ligação com os trabalhos agrícolas, as pessoas do agregado familiar. Situação que, naturalmente, não facilitava nada a sua inventariação e que nos levou a aceitar, algumas das vezes com reservas, as estatísticas industriais oficiais. Não fogem a isto os dados por nós apresentados no QUADRO V, quanto ao número de estabelecimentos de cardação e de apisoamento ${ }^{4}$.

Devido às características familiares desta indústria, pouco sabemos para além do seu número, pois nada nos é dito, por exemplo, sobre os valores da produção. Referem, no entanto, os responsáveis pelo Inquérito Industrial que, dos 47 pisões existentes no distrito, só alguns procediam ao aproveitamento da força da água. Faziam parte deste grupo os pisões que se localizavam nos concelhos de Castro Daire, Penedono, S. João da Pesqueira, Sátão, Tondela e Viseu. 


\section{QUADRO V \\ NÚMERO DE ESTABELECIMENTOS DE CARDAÇÃO \\ E DE PISÕES (1881)}

\begin{tabular}{|c|c|c|}
\hline Concelho & N. ${ }^{\circ}$ de empresas & N. ${ }^{\circ}$ de pisões \\
\hline CASTRO DAIRE & & 6 \\
\hline CINFÃES & 1 & 2 \\
\hline FRÁGUAS & 9 & 8 \\
\hline LAMEGO & 1 & 1 \\
\hline MANGUALDE & & 3 \\
\hline MOIMENTA DA BEIRA & 4 & \\
\hline MORTÁGUA & 1 & \\
\hline NELAS & 2 & \\
\hline OLIVEIRA DE FRADES & & 1 \\
\hline PENEDONO & & 1 \\
\hline S. PEDRO DO SUL & & 3 \\
\hline S.JOÃO DA PESQUEIRA & & 1 \\
\hline SÁTÃo & & 1 \\
\hline SERNANCELHE & & 2 \\
\hline TABOAÇO & & 1 \\
\hline TONDELA & & 7 \\
\hline VISEU & & 7 \\
\hline VOUZELA & 11 & 3 \\
\hline Total & 29 & 47 \\
\hline
\end{tabular}

Fonte: Inquérito Industrial de 1881, vol. II.

Ainda que não tivesse desaparecido de todo, a indústria de lanifícios acabou, como já referimos, por não vingar no distrito de Viseu. Não obstante, podemos dizer que em 1890, data da realização de mais um importante Inquérito Industrial, existia no concelho do Carregal do Sal, mais concretamente em Correlos, uma fábrica de Fiação e Tecelagem de Lã, pertencente a António da Silva Magalhães, onde laboravam 12 operários, incluindo o mestre, com uma remuneração que variava entre os $\$ 160$ e $\$ 120$ réis. Destes 12 trabalhadores, só oito eram maiores de 16 anos. Os quatro restantes, um tinha menos de 12 anos e os outros situavam-se entre os 12 e 16 anos de idade.

É sabido como o Inquérito Industrial de 1890 , ao contrário do de 1881 , se preocupou em diferenciar, segundo um critério nem sempre muito claro, a pequena indústria das fábricas. Porém, no que diz respeito a esta empresa de lanifícios, os 
inquiridores abstiveram-se de a classificar, muito embora não a incluíssem na pequena indústria, como o fizeram para o conjunto das outras empresas existentes no distrito. Aliás, pelo facto de a empresa ter mais de 10 operários, embora nem todos maiores, e de já utilizar uma máquina a vapor, ainda que apenas de $9 \mathrm{cv}$, não repugna incluir este estabelecimento na categoria de fábrica.

Por se tratar dos poucos estabelecimentos que, tendo em conta o referido Inquérito Industrial de 1890, não foi incluído na pequena indústria, pareceu-nos interessante ver se ela teria resistido ao crescente aumento da concorrência que se fez sentir no final do século. Pois, tendo em conta o capital fixo e circulante apresentado, de $4000 \$ 00$ e $800 \$ 000$ réis, respectivamente - note-se, só a título de curiosidade, que o capital fixo desta empresa era superior ao total do capital industrial do distrito em 1881, então de $3280 \$ 000$ réis, isto se tivermos em conta o que foi declarado aos responsáveis do Inquérito Industrial deste mesmo ano -, podemos dizer que se tratava de uma das empresas mais importantes do distrito. Ainda que em termos nacionais, como é óbvio, não tivesse grande significado.

Mantivemos os nossos intentos, apesar de nos ter parecido estranho que o seu proprietário, em resposta ao inquérito, tivesse apresentado valores de compra de matérias-primas, para o ano de 1889 , muito superiores aos que apresentou para a produção. Assim, ao declarar um gasto de $9580 \$ 00$ réis só em matérias-primas, sobretudo azeite e lã, e apenas $2100 \$ 000$ como valores brutos da produção, para o mesmo ano, das duas uma: ou estávamos em presença de uma tradicional subavaliação da produção, bastante generalizada nestes casos, como expediente para fugir a novas tributações, ou, a ser verdade, a empresa em causa estava em muito má situação. Provavelmente nunca saberemos toda a verdade sobre este caso, mas sobre o que não temos dúvidas é que, poucos anos mais tarde, já não existiam rastos deste estabelecimento. Curiosamente, a fonte que compulsámos - Boletim do trabalho Industrial, $\mathrm{n} .{ }^{\circ} 20$, que apresenta a indústria existente no distrito de Viseu, para o ano de 1907 - não só já não faz qualquer referência à fábrica em causa, como inclui o concelho do Carregal do Sal, a par dos concelhos de Armamar, Lamego, Mangualde, Moimenta da Beira, Mortágua, Nelas, Oliveira de Frades, Penalva do Castelo, Penedono, Santa Comba Dão, S. Pedro do Sul, Sernancelhe, Cinfães, Tabuaço e Tarouca, entre os que no distrito apenas possuem indústrias domésticas. A fonte referida indica-nos ainda que - para terminarmos esta incursão pelo sector dos lanifícios —, quanto a fábricas de lanifícios, ou mesmo de qualquer outro ramo têxtil, só o concelho de Tondela mantinha viva a tradição, com duas fábricas que empregavam 50 operários. Agora, já na primeira década do século XX, o sector que imperava, em termos industriais, era a produção de manteiga que, só por si, representava no distrito $47 \%$ das empresas instaladas e empregava $70,8 \%$ dos operários industriais. Facto tanto mais significativo se tivermos em consideração que a produção de manteiga, em termos industriais, não teve, pelo menos até 1890 , expressão significativa no distrito, não fazendo 
mesmo parte das estatísticas industrias, quer as que se fizeram a nível do país, como era o caso dos Inquéritios Industriais, quer mesmo das estatísticas distritais, casos dos relatórios apresentados pelo governador civil do distrito.

Aliás, durante toda a segunda metade do século XIX, a indústria que em termos quantitativos dominou, bem como a que mais cresceu, foi a de destilação de aguardente. $O$ que, aliás, não admira. Sobretudo, se tivermos em consideração que o distrito de Viseu foi, no século XIX, um dos mais importantes espaços económicos do país em produção vinícola. Assim, em 1887, por exemplo, o distrito de Viseu produziu 542000 hectolitros de vinho - o que representou, para esse ano, $10,2 \%$ da produção nacional —, quantidade apenas ultrapassada pelos distritos de Lisboa (885 500) e Santarém (587 900) (Boletim da Direç̧ão Geral da Agricultura, n. ${ }^{\circ}$, Março de 1889).

Assim, das 37 fábricas referenciadas pelo governador civil do distrito de Viseu, à Junta Geral do Distrito, em 1865, 32 eram de destilação de aguardente, o que representava $86,4 \%$ do total das empresas existentes.

\section{QUADRO VI}

FÁBRICAS EXISTENTES NO DISTRITO DE VISEU (1865)

\begin{tabular}{|c|c|c|c|c|}
\hline \multirow{2}{*}{ Concelhos } & \multicolumn{4}{|c|}{ Natureza e quantidade de fábricas } \\
\hline & $\begin{array}{c}\text { Destilação de } \\
\text { aguardente }\end{array}$ & $\begin{array}{c}\text { Curtumes e } \\
\text { couros }\end{array}$ & Papel & Pregagem \\
\hline ARMAMAR & 1 & & & \\
\hline CARREGAL & 10 & & & \\
\hline SANTA COMBA-DÃO & 1 & & & \\
\hline S. JOÃO DA PESQUEIRA & 3 & & & \\
\hline LAMEGO & 5 & & & \\
\hline NELAS & 3 & & & \\
\hline OLIVEIRA DE FRADES & 2 & & & \\
\hline TABUAÇO & 1 & & & \\
\hline TAROUCA & & & 1 & \\
\hline TONDELA & 2 & & & \\
\hline VISEU & 4 & 2 & & 2 \\
\hline Total & 32 & 2 & 1 & 2 \\
\hline
\end{tabular}


Para além das unidades de destilação de aguardente, apenas existiam 2 empresas de curtumes e couros, ambas no concelho de Viseu, já existentes em 1852, uma outra de papel, no concelho de Tabuaço e, por fim, mais duas de pregagem, também no concelho de Viseu.

Ainda assim, o número de estabelecimentos de destilação de aguardente, durante o século XIX, não parou de aumentar. Pois, se em 1856, como vimos, o número destes estabelecimentos era de 32 , um ano depois já existiam mais 4 , em 1873 o número subia a 56 e aquando da realização do Inquérito Industrial de 1881 a soma ascendia a 70 . Poucos eram os concelhos que não tinham uma fábrica de destilação de aguardente - em 1873, apenas os concelhos de Fráguas, S. João de Areias, Mortágua, S. Pedro do Sul, Resende, Sátão, Sernancelhe, Cinfães e Tarouca é que não possuíam destiladoras - , mas foi sempre o concelho do Carregal do Sal que manteve a maioria destes estabelecimentos: $10 \mathrm{em} 1865(31,2 \%$ do total), 12 em $1866(33,3 \%)$ e 13 em $1873(23,7 \%)$.

Não admira, portanto, que os técnicos responsáveis pelo Inquérito Industrial de 1881 tivessem visitado uma fábrica de destilação de aguardente - entre os poucos estabelecimentos que mereceram, no distrito de Viseu, esta distinção - e dela tenham deixado um relato circunstanciado. $O$ estabelecimento eleito pertencia a António Pais de Almeida, sito no lugar do Pinheiro, concelho de Mangualde. Esta fábrica, como então lhe chamaram, tinha sido fundada em 1866 e empregava um único homem, o maquinista, o qual vencia 300 réis diários, incluindo a alimentação. $O$ aparelho de destilação, apurou ainda a comissão, não diferia muito dos de outros distritos do país, bem como dos restantes 70 registados em outros concelhos do distrito.

Foi este tipo de empresa, pelo menos em termos quantitativos, que dominou o tecido industrial do distrito de Viseu, durante o século XIX. Pois, se em 1865 , como vimos, a destilação de aguardente representava $88,8 \%$ das empresas registadas no distrito, em 1866 este número apenas descia para 83,7\%. Cerca de oito anos mais tarde, em 1873, a relação quase não se alterava, mantendo-se nos $82,3 \%$. O peso, relativamente elevado, desta actividade acaba por ser um importante indicador do fraco desenvolvimento industrial do distrito. O QUADRO VII, que apresentamos mais adiante, é revelador do que acabamos de dizer. Assim, em 1873, para além das empresas de destilação de aguardente, apenas são referenciados mais 12 estabelecimentos, 9 dos quais no concelho de Viseu. Se compararmos estes dados com as indústrias existentes em 1865 (Ver QUADRO VI), é fácil apercebermo-nos que as indústrias existentes na altura ainda perduram e que o panorama industrial do distrito apenas se animou um pouco: cinco indústrias em 1865 e, oito anos depois, apenas mais sete. Destas, só quatro é que eram novas indústrias, inexistentes, portanto, antes de 1865. Referimo-nos às empresas de fiação de seda, nos concelhos de Lamego e de Sernancelhe e a mais duas, de moagem e de chapéus, ambas no concelho de Viseu. 


\section{QUADRO VII}

NATUREZA E NÚMERO DE FÁBRICAS NO DISTRITO DE VISEU EM 1873

\begin{tabular}{|c|c|c|c|c|c|c|c|}
\hline Concellho & $\begin{array}{c}\text { Destilação } \\
\text { de } \\
\text { aguardente }\end{array}$ & $\begin{array}{c}\text { Curtumes } \\
\text { e } \\
\text { couros }\end{array}$ & Papel & Pregagem & $\begin{array}{c}\text { Moagem } \\
\text { de } \\
\text { cereais }\end{array}$ & $\begin{array}{c}\text { Fiąäa } \\
\text { de } \\
\text { seda }\end{array}$ & Chapéus \\
\hline 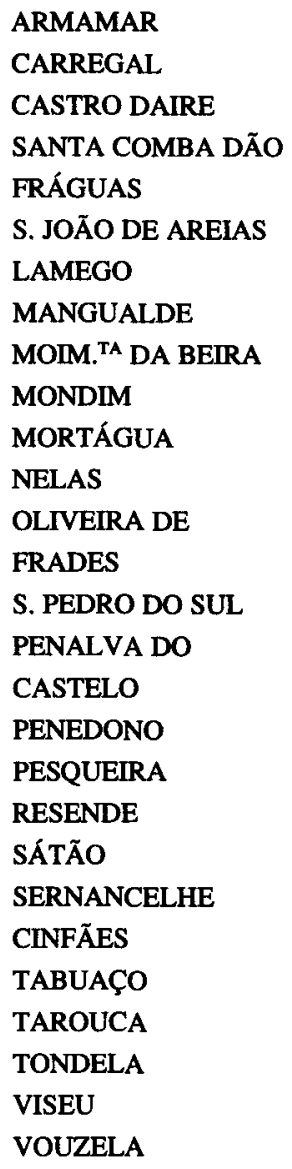 & $\begin{array}{r}3 \\
13 \\
3\end{array}$ & 3 & 1 & 4 & 1 & 1 & 1 \\
\hline Total & 56 & 3 & 1 & 4 & 1 & 2 & 1 \\
\hline
\end{tabular}

Fonte: Relatório Apresentado d Junta Geral do Distrito de Viseu, pelo Governador Civil do mesmo Distrito, em 1873, Viseu, Imprensa do Governo Civil, 1873.

Muitas das empresas que constam do QUADRO VII ainda existiam em 1881, aquando da realização do Inquérito Industrial. Algumas delas, como foram os 
casos das fábricas de moagem e de curtumes, ambas no concelho de Viseu, e de fiação de seda, no concelho de Sernancelhe, responderam mesmo ao inquérito, o que, como se compreende, permite fazer uma ideia do seu estado e evolução.

Comecemos pela fábrica de moagem, fundada em 1865 , pertencente a Joaquim Pereira da Silva. Curiosamente, foi esta a primeira fábrica a utilizar uma máquina a vapor no distrito de Viseu. Raridade que, talvez por esse facto, foi minuciosamente descrita pela comissão de inquérito como sendo de forma horizontal, tendo sido construída, bem como a caldeira, na Fundição de Massarelos ${ }^{5}$, no Porto. Como combustível, a referida máquina alimentava-se não de carvão, caro e de difícil acesso, mas de lenha de pinho, mais barata e acessível.

Não conseguimos, no entanto, apurar se a aquisição da máquina terá sido feita no ano da fundação da fábrica, mas tudo indica que a sua compra se tivesse efectuado no início de laboração, ou, então, poucos anos depois ${ }^{6}$. Um investimento como este, ainda que a máquina tivesse apenas $12 \mathrm{cv}$, só se justificava se as perspectivas de lucros fossem boas. Ora, a situação económica da empresa e o quadro económico em que esta desenvolvia a sua actividade eram, no início da década de 80 , muito menos favoráveis do que nas décadas anteriores. As responsabilidades por este novo quadro de crise iam inteirinhas para a forte concorrência que as farinhas vindas de Lisboa estavam a fazer aos moageiros locais? ${ }^{7}$. Aliás, o proprietário refere mesmo que na sua empresa já trabalharam, no passado, 9 operários, enquanto que no presente (1881) apenas nela laboravam três trabalhadores, os quais faziam em média dez horas por dia, vencendo um salário desigual de 240 , 400 e 600 réis.

A maior parte do trigo moído neste estabelecimento, ao contrário do centeio que era todo originário do distrito, era importado dos E.U.A. A Viseu chegava via cidade do Porto, onde residiam os responsáveis pela sua importação. Os outros locais de abastecimento de trigo, ainda que em menores quantidades, eram, sobretudo, a Espanha e a cidade da Guarda. A preferência pelo trigo americano, substancialmente mais caro que o espanhol, ou mesmo que o português - o trigo espanhol e português regulava os 600-700 réis, enquanto que o americano, incluindo o transporte, andava pelos 750 a 800 réis -, encontra explicação na preferência que os padeiros tinham pela farinha americana, a qual proporcionava a feitura de «um pão mais branco, com melhor aparência, e, portanto, mais vendável» (Inquérito Industrial, de 1881, vol. II: 82). Ora, a farinha que vinha de Lisboa, e que tanta concorrência fazia em Viseu, era quase toda de origem americana, sendo ela, como vimos, a preferida, apesar de mais cara, pelos padeiros da cidade. À fábrica de moagem de Viseu só lhe restava adquirir, também ela, trigo de origem americana para satisfazer os gostos de padeiros e consumidores, mas como competir com os processos de moagem mais modernos da capital? Está aqui, por certo, a explicação para o facto de, em 1890, já não haver nenhum estabelecimento de moagem no concelho de Viseu que utilizasse qualquer máquina a vapor. 
A utilização exclusiva de energia hidráulica —que, aliás, mesmo nesta empresa, nunca deixou de existir - , mais barata, foi a forma encontrada para diminuir os custos de produção, ainda que à custa de uma menor produtividade. Aqui, a exemplo de outros sectores, a concorrência não deixou alternativa; para a história ficou, no entanto, o facto de terem sido esta empresa e este sector, no distrito de Viseu, os pioneiros na utilização da energia que ainda hoje perdura como símbolo da primeira revolução industrial ${ }^{8}$.

Se tomarmos como referência o ano de 1852, no distrito de Viseu, para além da tradicional indústria doméstica, existiam apenas duas unidades industriais, as quais ocupavam 5 operários cada uma. Ambas as empresas referidas se dedicavam à produção de curtumes.

Uma delas - a fábrica de David \& $c^{a}$, situada na própria cidade de Viseu — foi fundada em 1840 e manteve-se sempre em laboração até, pelo menos, à década de oitenta. Em 1907, existia ainda em Viseu uma fábrica de curtumes; não pudemos, no entanto, confirmar se se tratava do mesmo estabelecimento. Registe-se, contudo, mesmo que não se trate da mesma fábrica, a manutenção de uma actividade, na cidade de Viseu, que já vinha desde a década de 40 do século XIX. Apesar desta longevidade - e a tratar-se do mesmo estabelecimento - , não podemos dizer que tivesse mudado muito a sua dimensão, pelo menos se tivermos em consideração a mão-de-obra empregue. Em 1852, como vimos, empregava 5 trabalhadores, em 1881 o número de operários subiu apenas para 6. E se, em 1907, a empresa fosse ainda a mesma, o salto também não pode ser considerado de grande monta, dado que apenas empregava 12 operários.

Quanto à segunda empresa, também de curtumes, o que podemos acrescentar, desde logo , é que teve uma vida substancialmente mais curta que a referida anteriormente. Fundada em 1848, a três quilómetros da cidade de Viseu, mais concretamente em Rio de Loba, estava em 1881, quando foi visitada pela comissão ligada ao Inquérito Industrial, em vésperas de fechar. Os seus proprietários - Viúva Lobão \& Filhos, que também detinham, no concelho de Viseu, uma empresa ligada à indústria de pregagem - salientaram as dificuldades económicas que entretanto atravessavam, em ambos os ramos, estando na disposição de abandonar estas actividades. As razões invocadas foram, invariavelmente, a forte concorrência que se fazia sentir na região, bem como a dificuldade de acesso a matérias-primas, as quais lhes chegavam sempre bastante oneradas pelos custos de transporte.

Ambas as empresas de curtumes referidas produziam para consumo local, sendo, no entanto, referida a feira de Mangualde como o local de venda privilegiado.

Deixámos para o fim a produção de casulo e fio de seda que, tal como em outros distritos do interior - David Justino afirma mesmo que a sericultura continuava a ser, nos meados meados do século XIX, uma actividade do interior 
(Justino, 1988:70)—, conheceu no distrito de Viseu, na segunda metade do século XIX, algum incentivo e crescimento. Realidade que confirma aquilo que Miriam Halpern Pereira vem afirmando quando identifica o surto sericícola com o modelo económico da Regeneração, em que o comércio externo desempenhou o papel de motor (M. H. Pereira, 1983:119). A retoma da produção sericícola, depois de alguns anos de profunda decadência, aparece, assim, ligada a uma favorável «conjuntura internacional que se traduzia numa procura cada vez maior de casulo e fio de seda" (D. Justino, 1988:68). É, portanto, neste quadro favorável de uma maior procura do casulo e fio de seda que devemos entender, não só o aumento da sua produção no distrito de Viseu, como a fundação de duas fábricas de fiação de seda, como já fizemos referência (ver QUADRO VII).

\section{QUADRO VIII}

PRODUÇÃO DE CASULO E FIO DE SEDA NO DISTRITO DE VISEU (1851-72)

\begin{tabular}{|c|c|c|}
\hline Anos & Produção de casulo (kg) & Produção de fio (kg) \\
\hline 1851 & 9434640 & \\
1852 & 6302376 & 503,880 \\
1864 & 14097 & \\
1872 & 33774892 & 406,930 \\
\hline
\end{tabular}

Fonte: Relatórios apresentados à Junta Geral do Distrito de Viseu, pelo Governador Civil do Mesmo Distrito, Viseu, Imp. do Governo Civil, anos de 1865 e 1873; Anos 1851 e 1852, D. Justino, vol. II, 1988:70

Todavia, em 1881, tudo indica que os ventos favoráveis, sobretudo externos, que haviam trazido um novo alento a esta indústria tradicional, tinham mudado?. Como que a confirmar isto mesmo, temos o testemunho do proprietário da Fábrica Francisco Cabral Pais \& Filhos, sita em Vila da Rua, Concelho de Sernancelhe, que, apesar dos muitos conselhos que apresenta à comissão para a proteç̧ão desta actividade e das muitas esperanças que ainda deposita nela, não esconde o seu desapontamento e, no essencial do seu discurso, parece referir-se mais ao tempo passado do que à respectiva actualidade, sobretudo quando afirma que «Nós mesmos faziamos compras relativamente importantes para o fabrico; de sementes chegámos a exportar em quantidades de 300 Kilogramas até o anno de 1873» (Inquérito Industrial de 1881). Está bem presente nesta afirmação a conjuntura favorável que a sericultura viveu e, sobretudo, o incentivo e a importância que a exportação do casulo da seda teve para o retomar de uma actividade, outrora importante. 


\section{QUADRO IX}

PRODUÇÃO DE SEDA EM FIO, PREÇO E LOCAL DE VENDA (1872)

\begin{tabular}{|l|c|c|l|}
\hline \multicolumn{1}{|c|}{ Concelho } & Produção(KG) & Preço por KG & \multicolumn{1}{|c|}{ Local de Venda } \\
\hline ARMAMAR & 45 & $10 \$ 000$ & Vendida no Porto \\
LAMEGO & 74 & $11 \$ 000$ & Exportada para França \\
MANGUALDE & 91,800 & $2 \$ 600$ & Não refere \\
NELAS & & $23 \$ 600$ & Não houve venda \\
RESENDE & 12 & $8 \$ 500$ & Vendida no Porto \\
SERNANCELHE & 150 & $5 \$ 000$ & Vendida para Itália \\
CINFÃES & 32,130 & $14 \$ 000$ & Vendida no Porto \\
\cline { 2 - 4 } & & & \\
& 406,930 & & \\
\hline \multirow{2}{*}{ Total } & & & \\
\hline
\end{tabular}

Fonte: Relatório Apresentado d Junta Geral do Distrito de Viseu, pelo Governador Civil do mesmo Distrito, em 1865, Viseu, Imp. do Governo Civil, 1865.

Uma parte importante da produção de seda em fio destinava-se à exportação, sobretudo para França e Itália. A cidade do Porto servia, normalmente, de intermediária no processo de exportação. Ainda assim, muitos dos compradores estrangeiros optaram por ir mesmo ao local da produção, evitando deste modo pagar os custos da intermediação (Pereira, 1993:126)

A produção do fio não se cingia apenas aos concelhos onde se encontravam registadas fábricas de fiação de seda - casos de Lamego e Sernancelhe -, o que pressupõe a existência de uma indústria doméstica, dispersa pelos concelhos, não registada e, portanto, não contributiva. Aliás, no concelho de Mangualde não se encontra declarada nenhuma indústria de fiação de seda; contudo, foi um dos concelhos que, em 1872, mais produziu.

Este reanimar da indústria doméstica, ligada à fiação de seda, encontra explicação numa conjuntura favorável de grande procura externa. Alterada a conjuntura, pouco restou deste entusiasmo e a débil indústria, que nunca deixou de o ser, desaparece sem deixar grande rasto. É importante, por isso, reconhecer que esta actividade, mesmo no seu melhor período, esteve sempre longe - fora de uma conjuntura de excepção, como, afinal, foi o caso - de um qualquer crescimento sustentado.

Por último, resta-nos fazer referência à energia utilizada pela indústria no distrito de Viseu, já que, através deste importante indicador, é possível, de alguma forma, conhecer a sua estrutura produtiva e ter uma percepção mais aproximada da evolução e modernização que este sector económico conheceu. 
Em 1881, aquando da elaboração do Inquérito Industrial, apenas funcionava no distrito uma máquina a vapor $e$, tendo em conta os dados apresentados por este inquérito, três rodas hidráulicas. Ainda que estes resultados, sobretudo quanto às rodas hidráulicas, não estejam de acordo com a realidade - há que ter em atenção que os números apresentados no Inquérito Industrial apenas dizem respeito às empresas que responderam ao questionário que, no caso do distrito de Viseu, só cobriu 43 unidades industrias, muito embora tivessem sido convidadas a responder 225 -, eles não deixam de evidenciar, como temos vindo a referir, uma estrutura industrial reduzida à pré-indústria, com características marcadamente oficinais.

\section{QUADRO X}

UTILIZAÇÃO ENERGÉTICA E RESPECTIVAS ACTIVIDADES POR CONCELHO (1890)

\begin{tabular}{|c|c|c|c|c|}
\hline Concelho & $\begin{array}{c}\text { N. }{ }^{\circ} \text { de máquinas } \\
\text { de vapor }\end{array}$ & $\begin{array}{c}\text { Sector de } \\
\text { actividade }\end{array}$ & $\begin{array}{l}\text { N.`ode rodas } \\
\text { hidráulicas }\end{array}$ & $\begin{array}{c}\text { Sector de } \\
\text { actividade }\end{array}$ \\
\hline $\begin{array}{l}\text { CARREGAL } \\
\text { FRÁGUAS } \\
\text { LAMEGO } \\
\text { MANGUALDE } \\
\text { MONDIM } \\
\text { MORTÁGUA } \\
\text { NELAS } \\
\text { PENEDONO } \\
\text { RESENDE } \\
\text { S. COMBA DÃO } \\
\text { S. J.DE AREIAS } \\
\text { S. P. DO SUL } \\
\text { SÁTÃO } \\
\text { SERNANCELHE } \\
\text { CINFÃES } \\
\text { TABUAÇO } \\
\text { TAROUCA } \\
\text { TONDELA } \\
\text { VISEU }\end{array}$ & $\begin{array}{l}1 \\
1\end{array}$ & moagem & $\begin{array}{c}77 \\
73 \\
33 \\
37 \\
28 \\
39 \\
\\
71 \\
\\
74 \\
18 \\
28 \\
1 \\
1 \\
32 \\
24 \\
2 \\
17 \\
47 \\
76 \\
\\
28\end{array}$ & $\begin{array}{l}\text { lã-apisoamento(5) } \\
\text { moagem (72) } \\
\text { moagem } \\
\text { moagem } \\
\text { moagem } \\
\text { moagem } \\
\text { lã-apisoamento(4) } \\
\text { moagem (35) } \\
\text { lã-apisoamento(1) } \\
\text { moagem(70) } \\
\text { moagem } \\
\text { moagem } \\
\text { moagem } \\
\text { linho-marragem } \\
\text { moagem } \\
\text { moagem } \\
\text { moagem } \\
\text { pólvora } \\
\text { moagem } \\
\text { moagem } \\
\text { moagem(73) } \\
\text { lã-apisoamento(1) } \\
\text { serralharia(1) } \\
\text { moagem }\end{array}$ \\
\hline Total...... & 7 & & 706 & \\
\hline
\end{tabular}


Se compararmos a situação apresentada pelo Inquérito Industrial de 1881 - três rodas hidráulicas e uma única máquina a vapor - com aquilo que se passava aquando da realização do Inquérito Industrial de 1980, podemos dizer que, no espaço de 9 anos, o potencial energético empregue na indústria aumentou consideravelmente. Ainda que esta comparação tenha que ser ponderada, dada a subavaliação que foi feita em 1881, especialmente na energia hidráulica utilizada, não podemos deixar de registar que, em 1890, estavam em actividade 7 máquinas a vapor - quatro na moagem, todas no concelho de Penedono, um na fiação de lã, concelho do Carregal, outra na serralharia, concelho de Fráguas e, por fim, mais uma no concelho de Tabuaço - e 706 rodas hidráulicas.

$\mathrm{O}$ recurso à força da água, por parte das unidades industriais, representa, em $1890,99 \%$ das opções utilizadas. Sendo que a parte mais importante desta energia é utilizada pelo sector moageiro, $97,7 \%$ das rodas hidráulicas estão relacionadas com a moagem de cereais.Para além deste sector, resta o apisoamento de lã, com 11 rodas hidráulicas, uma fábrica de pólvora que, para além de uma máquina a vapor, também utiliza duas rodas hidráulicas e, por último, serralharia e marragem de linho, uma roda cada.

\section{CONCLUSÃO}

Podemos dizer, se tivermos em consideração os sectores industriais mais importantes - casos, por exemplo da destilação da aguardente e da moagem que a indústria no distrito de Viseu, durante o século XIX, para além de nunca ter deixado de ser dominada pela estrutura oficinal, ou, se preferirmos, pré-industrial, esteve sempre ligada à transformação de produtos disponíveis na área envolvente. $\mathrm{E}$, neste quadro, não admira que a quase totalidade da produção industrial não tivesse outras ambições que a satisfação do mercado local e mesmo familiar. Por outro lado, a estreita ligação da indústria às actividades agrícolas, quer enquanto fornecedoras de matérias-primas, quer mesmo como complemento económico, leva muitas vezes à confusão de não se saber, em muitos casos, qual seria a actividade privilegiada pelos agentes envolvidos. Aliás, só a esta luz se explica que no Inquérito Industrial de 1881 apenas se reconheça a existência de 74 operários ligados à indústria, dos quais 60 são homens, 2 são mulheres e 12 menores.

A abertura de novas estradas, bem como o caminho-de-ferro, trouxeram, naturalmente, a aproximação e a integração de novos mercados até aqui resguardados e protegidos. Nas novas vias de comunicação viram os vários poderes, regionais e nacionais, a panaceia de todos os males. Porém, como tantas vezes acontece, com esta modernização, sem dúvida inadiável e necessária, quem mais aproveitou foram os pólos, na altura, mais desenvolvidos economicamente. Estes passaram a ter mais facilidades no escoamento dos seus produtos, chamando a si o domínio 
de mercados que, por via da sua interioridade ou dificuldade de acessos, estiveram até então protegidos. Aliás, esta é a outra face da moeda, nem sempre bem analisada, pois a construção de novas vias de comunicação não trouxe só melhores facilidades num sentido - como sejam menores custos no abastecimento de matérias-primas, maior facilidade no escoamento de produtos, maiores investimentos - trouxe, sobretudo, maiores facilidades aos centros mais desenvolvidos para integrarem no seu espaço económico regiões periféricas que, até aqui, escapavam, de todo ou em parte, ao seu domínio. Por outras palavras, o desenvolvimento das vias de comunicação acelerou, nos finais do século XIX, a formação do espaço económico nacional - para utilizarmos o conceito desenvolvido recentemente por David Justino, na obra já por várias vezes aqui citada; contudo, esta modernização das infra-estruturas, benéfica a longo prazo, teve, no primeiro impacto, o condão de não só pôr a nu a fragilidade das estruturas produtivas industriais, comerciais e agrícolas de algumas regiões, mas, mais importante ainda, acabou por ter um efeito, em grande medida, contrário ao que dela sempre esperaram os agentes locais envolvidos. Assim, podemos dizer que o distrito de Viseu, em muitos aspectos ainda apegado a uma mentalidade e estruturas produtivas de Antigo Regime, pouco ou nada aproveitou, em termos industriais e no curto prazo, das melhorias evidentes trazidas pelas novas vias de comunicação. Podendo mesmo afirmar-se que a maior facilidade de circulação de produtos, que se fez sentir no último quartel do século XIX, mais não fez do que apressar a morte de uma indústria doméstica existente, sem que no seu lugar despontassem modernos estabelecimentos industriais, com capacidade para romperem com os modelos tradicionais de produção. E assim, no quadro de uma nova divisão social do trabalho, nacional e internacional, que acabou por caracterizar, sobretudo, a segunda metade do século XIX, o distrito de Viseu, podemos dizê-lo, não só não conseguiu apanhar o comboio da modernização do seu aparelho produtivo, como acabou, tal como outras regiões do país, por atrofiar alguns dos sectores que entretanto despontavam. Ainda que o distrito viseense nunca tivesse tido uma importante tradição industrial, esta região corresponde na perfeição ao modelo conhecido que liga o moderno crescimento económico, pelo menos na sua fase inicial, ao acentuar das assimetrias. Não nos cabe agora aqui medir o alargamento deste fosso, cavado sobretudo a partir da segunda metade do século XIX, mas não temos dúvidas sobre o acentuar do atraso económico do distrito, em relação às regiões do país mais industrializadas, durante o período que aqui nos ocupa.

Aliás, a realidade deste quadro, muito embora, naturalmente, sem a perspectiva histórica que hoje podemos ter, não escapou ao Governador Civil do distrito, Visconde de Guedes Teixeira que, profundamente desanimado com o número e fraco nível das respostas dadas pelos industriais do distrito ao Inquérito Industrial de 1881, desabafava: «o numero de questionarios respondidos é lemitadissimo [...] só servem para testemunhar o grande atrazo em que se acha a população industrial 
d'este districto, falha de toda a instrução elementar, alheia a todos os progressos da moderna indústria, e não obedecendo no seu improbo labutar, senão ao impulso esterilisador da rotina» (Inquérito Industrial de 1881, vol. III:35). E, depois de salientar que não era por falta de condições naturais que o distrito não desenvolvia a sua indústria - acreditando mesmo que das respostas ao inquérito podiam sair algumas ideias capazes de contribuir para o inverter da situação-, o Governador Civil não esconde o seu sentimento de impotência perante uma realidade bem evidente na pobreza das respostas ao referido inquérito; o que, saliente-se, não o apanha desprevenido: «não é de surprehender, visto como na actualidade a indústria n'este districto quasi se limita à satisfação das exiguas necessidades dos mercados locaes, quando não tem por unico alvo a das necessidades caseiras» (idem:35).

Retrato que ainda não tinha sofrido alterações sensíveis em 1907, se tivermos em linha de conta que, por esta altura, 16 dos 23 concelhos do distrito - entre os quais se contavam concelhos tão importantes com Lamego, Santa Comba Dão, Nelas, etc. - não conheciam qualquer actividade industrial digna desse nome.

\section{NOTAS}

* O presente artigo beneficiou e muito com a leitura atenta e crítica do Prof. Doutor José M. Amado Mendes que, ao texto inicial, fez comentários e sugeriu alterações, atitude que, naturalmente, agradecemos.

1. Sobre este assunto, ver José M. Amado Mendes, A Àrea Económica de Coimbra - estrutura e desenvolvimento industrial, 1867-1927, Coimbra, Comissão de Coordenação da Região Centro, 1984, p.25-30.

2. Um estudo relativamente recente de Alberto Martinho vem confirmar estes dados ao considerar que $43 \%$ das empresas existentes na região foram constituídas entre 1980 e 1989 e 28,18\% entre1970-1979, salientando-se no mesmo trabalho que o sector primário ainda ocupava em 1981 - tendo em conta a população agrícola que trabalhava na exploração em 1979 e a população presente em $1981-43,75 \%$ das pessoas(Alberto Martinho, «A indústria no Distrito de Viseu «Subsídios para o seu estudo», Gestão e Desenvolvimento, n. ${ }^{\circ}$ 1, 1992, p. 3-33.

3. Entre 1866 e 1871 , a média anual de emigrantes no distrito de Viseu foi de 390 . Porém, alguns anos mais tarde, 1880-1882, a média anual já atingia 1474. Para em 1896-1898 atingir a segunda média anual do país - foi apenas superior no distrito do Porto - com um saldo emigratório de 2699 pessoas. Por sua vez, nos anos de 1911-1913, o distrito de Viseu é, claramente, o distrito com um saldo emigratório maior, com uma média anual de 10156 emigrantes (M. Halpern Pereira, Livre-Câmbio e Desenvolvimento Económico, Lisboa, Sá da Costa Editora, 1993, p. 365).

4. Sobre a necessidade de recorrer a outras fontes, para além dos inquéritos industriais, ver, entre outros, J. M. Amado Mendes, «Etapas e limites da industrialização», História de Portugal (Dir. José Mattoso), Volume 5, Lisboa, Círculo de Leitores, 1993, p. 360. 
5. A título de curiosidade, diga-se que a Fundição de Massarelos foi fundada, no Porto, em 1852.

6. Podemos, no entanto, adiantar que, no ano de 1873 , já lá se encontrava instalada uma máquina a vapor, sendo este facto testemunhado po Eduardo Coelho. A propósito, escreveu este autor: «pode moer quatro ou seis mil moios de farinha por semana. Aquele homem [o proprietário], que arriscou ali o melhor da sua fortuna, representa o génio da indústria moderna» (Passeios na Província, I, p. 33, apud Joel Serrão, Temas Oitocentistas I, Lisboa, Livros Horizonte, 1980, p. 71).

7. Esta concorrência foi sentida em outras regiōes do país, como foi o caso do Alentejo. Sobre esta região, cf. Hélder Dias Fonseca, Economia e Atitudes Económicas no Alentejo Oitocentista, vol. 1, Évora, 1992, p. $42-43$ (Dissertação de doutoramento, mimeog.).

8. Sobre o significado da aplicação à indústria da máquina a vapor, ver José M. Amado Mendes, «A indústria portuguesa no século XIX. Achegas para o seu estudo», Prelo, n. ${ }^{\circ} 7$ Abril/Junho, 1985, p. 23-31.

9. Na opinião de M. Halpern Pereira, o entusiasmo com a sericultura, sobretudo no período que vai de 1852 a 1876, encontrava-se completamente desfeito neste último ano, pela falta de mercado exterior, principal responsável pelo surto neste sector (ob. cit., p.126)

\section{FONTES E BIBLIOGRAFIA}

\section{I - FONTES}

Anuário Estatístico de Portugal.

Boletim da Direç̧ão Geral de Agricultura, século XIX.

Boletim do Trabalho Industrial, n. ${ }^{\circ} 20$, Lisboa, Imprensa Nacional, 1908.

Censo da População do Reino de Portugal (1890), Lisboa, Imprensa Nacional, 1896.

Censo da População do Reino de Portugal (1900), Lisboa, Imprensa Nacional, 1905.

Inquérito Industrial de 1881, Lisboa, Imprensa Nacional, 1883.

Inquérito Industrial de 1890, Lisboa, Imprensa Nacional, 1891.

Relatórios Apresentados à Junta Geral do Distrito de Viseu (1865-1889).

\section{II - BIBLIOGRAFIA}

CASCÃO, Rui, 1993, «O crescimento demográfico - ritmos e factores», História de Portugal (Dir. José Mattoso), 5. ${ }^{\circ}$ Vol., Lisboa, Círculo de Leitores, p. 425-439.

FONSECA, Hélder Adegar T. Dias, 1992, Economia e Atitudes Económicas no Alentejo

Oitocentista, 2 vols., Évora (Dissertação de Doutoramento, mimeog.).

JUSTINO, David, 1988- 1989, A Formação do Espaço Económico Nacional - Portugal 1810$-1913,2$ Vols., Lisboa, Vega.

MACEDO, Jorge Borges, 1982, Problemas de História da Indústria Portuguesa no Século XVIII, Lisboa, Querco. 
MARTINHO, Alberto, 1992, «A indústria no distrito de Viseu (subsídios para o seu estudo)», Gestão e Desenvolvimento, $\mathrm{n} .^{\circ}$ 1, p.3-33.

MENDES, J. Maria Amado Mendes, 1993, «Etapas e limites da industrialização», História de Portugal (Dir. José Mattoso), 5. ${ }^{\circ}$ Vol., Lisboa, Círculo de Leitores, p. 355-367.

MENDES, J. Maria Amado, 1985, «A indústria portuguesa no século XIX. Achegas para o seu estudo», Prelo, n. ${ }^{\circ}$ 7, Abril/Junho, p. 23-32.

MENDES, J. Maria Amado Mendes, 1984, A Área Económica de Coimbra - Estrutura e Desenvolvimento Industrial, 1867-1927, Coimbra, Comissão de Coordenação da Região Centro.

NUNES, Ana Bela, 1991, «A evolução da estrutura, por sexos, da população activa em Portugal - um indicador do crescimento económico (1890-1981)», Análise Social, n. ${ }^{\circ} 112-113$, p. 707-722.

PEREIRA, Miriam Halpern, 1974, Assimetrias de crescimento e dependência externa, Lisboa, Seara Nova.

PEREIRA, Miriam Halpern, 1983, Livre Câmbio e Desenvolvimento Económico - Portugal na segunda metade do século $X I X, 2{ }^{a}$ edição, Lisboa.

REIS, Jaime, «A industrialização num país de desenvolvimento lento e tardio: Portugal, 1870-1913», Análise Social, n. ${ }^{\circ}$ 96, 1987, p. 207-227.

REIS, Jaime, 1984, «O atraso económico português em perspectiva histórica (1860-1913)», Análise Social, vol. XX (80), p.7-28.

SILVEIRA, Joaquim Henriques Fradesso da, 1864, As Fábricas de Portugal - Indagações Relativas aos Tecidos de Lä, Lisboa, Imprensa Nacional. 